\title{
Xylazine-induced reduction of tissue sensitivity to insulin leads to acute hyperglycemia in diabetic and normoglycemic monkeys
}

Yong-Fu Xiao*, Bingdi Wang, Xiaoli Wang, Fenglai Du, Michael Benzinou and Yi-Xin Jim Wang

\begin{abstract}
Background: The $a_{2}$-adrenoceptor agonist xylazine as an anesthetic has been widely used either alone or in combination with other anesthetics, such as ketamine, in veterinary clinic and research. In the last decade xylazine has been used in drug abusers in certain geographic area. This study investigated the effects of xylazine on blood glucose level and insulin secretion in normoglycemic and insulin-dependent diabetic monkeys.

Methods: Both adult cynomolgus $(n=10)$ and rhesus $(n=8)$ monkeys with either sex were used in the study. Xylazine (1-2 mg/kg) was administrated intramuscularly. Blood glucose, insulin, glucagon and glucagon-like peptide 1 in overnight-fasted monkeys were measured immediately before and after xylazine administration. The hyperinsulinemic-euglycemic clamp method was used in the study for assessing the potential mechanism of xylazine-induced hyperglycemia.

Results: Xylazine administration increased the blood glucose levels from $58 \pm 3$ to $108 \pm 12 \mathrm{mg} / \mathrm{dL}$ in normoglycemic ( $n=5, p<0.01)$ and from $158 \pm 9$ to $221 \pm 13 \mathrm{mg} / \mathrm{dL}$ in insulin-dependent diabetic $(n=5, p<0.01)$ monkeys and was not accompanied by any significant changes in blood insulin, glucagon, and glucagon-like peptide-1. Xylazine-induced hyperglycemia occurred within 10 min and reached the peak at 35 min after injection. Xylazine-induced hyperglycemia declined slowly in diabetic animals. The $a_{2}$-adrenoceptor antagonist yohimbine was administrated to bring down the elevated glucose level to the pre-xylazine one in 4 out of 5 diabetic animals. To assess the potential mechanism, the hyperinsulinemic-euglycemic clamp was used to maintain a nearly saturated and constant insulin level for minimizing endogenous insulin glucoregulation. Xylazine administration decreased glucose infusion rate, from $14.3 \pm 1.4$ to $8.3 \pm 0.8 \mathrm{mg} / \mathrm{min} / \mathrm{kg}(n=6, p<0.01)$ in normoglycemic rhesus monkeys, which indicates that the glucose metabolic rate ( $M$ rate) was decreased by xylazine. In addition, after clamping blood glucose level in a range of 55 to $75 \mathrm{mg} / \mathrm{dL}$ for 40 min with constant glucose infusion, xylazine administration still increased blood glucose concentration.
\end{abstract}

Conclusions: We conclude that xylazine administration induces hyperglycemia in normoglycemic and insulindependent diabetic monkeys potentially via stimulation of $\mathrm{a}_{2}$-adrenoceptors and then reducing tissue sensitivity to insulin and glucose uptake.

Keywords: Xylazine, Hyperglycemia, Monkey, Insulin, Glucose

\footnotetext{
* Correspondence: xiaoyongfu@crownbio.com

Cardiovascular and Metabolic Disease Research, Crown Bioscience Inc,

Science and Technology Park, 6 Beijing West Road, Taicang Economic

Development Area, Jiangsu Province 215400, The People's Republic of China
} 


\section{Background}

Xylazine is an $\alpha_{2}$-adrenoceptor agonist and shares the similar pharmacological properties with clonidine [1-4]. It has been widely used as a drug for sedation and analgesia in veterinary clinic and non-human mammal research for several decades $[5,6]$. It can relieve pain and relax skeletal muscle. Xylazine is often co-administrated with ketamine to provide reliable anesthesia effects $[7,8]$. The sedative and muscle-relaxing properties of xylazine can be beneficial in reducing ketamine-induced side effects, such as tremor and muscle rigidity. It also can reduce animal gastric and intestinal motility during gastrointestinal surgery or endoscopy. Its analgesic action is less than $30 \mathrm{~min}$, but its sedative effect can last 2 hrs. Xylazine has adverse effects (e.g., cardiac conduction disturbances, bradycardia, and myocardial depression) similar to other $\alpha_{2}$ agonists. These adverse effects can be attenuated, blocked or reversed by adrenergic $\alpha_{2}$-receptor antagonists such as yohimbine $[9,10]$.

Maintaining blood glucose homeostasis involves complex neurohumoral regulation. Stress can increase blood glucose by changing several hormones including insulin, glucagon, GLP-1, and catecholamines [11,12]. Administration of the potent $\alpha_{2}$ agonist xylazine can result in a neurohumoral imbalance which affects blood glucose. In fact, several studies demonstrate that administration of xylazine increases blood glucose in various animal species, including dogs, cats, rats, and mice [12-16].

Currently, xylazine is not authorized for human use. However, early studies showed that xylazine induced sedation, muscle relaxation, and analgesia in healthy volunteers $[17,18]$. All volunteers in those studies exhibited a significant reduction of blood pressure and heart rate. Interestingly, xylazine effectively lowered blood pressure and heart rate in some hypertensive patients $[18,19]$. This veterinary anesthetic compound has been used as a new recreational drug among drug abusers in certain geographic areas [20-24]. Chronic use of this substance induces physical dependence and open skin ulcers or abscesses [25]. More severe intoxication has been reported in xylazine users [19] and post-mortem examinations have attributed the death to xylazine (26-29). Medical examination in some drug-related deaths detected xylazine concurrently [26-29].

Previous studies show that xylazine increases blood glucose in both small and large animals [12-14]. However, the effects of this drug on blood glucose homeostasis in non-human primates (NHPs) are unclear. The present study investigates the effects of xylazine on blood glucose in fasted, ketamine-anesthetized monkeys with or without diabetes. We also assessed xylazine's effects on the secretion of insulin, glucagon, and glucagonlike peptide 1 (GLP-1). Understanding xylazine pharmacology and adverse effects in NHPs can provide useful information regarding its use in veterinary clinics and animal research as well as for proper therapy of abusers intoxicated with this $\alpha_{2}$-adrenoceptor agonist.

\section{Methods}

\section{Animal care and procedures}

Experiments were carried out in cynomolgus (Table 1) and rhesus monkeys of either sex. These monkeys were individually housed and maintained in our animal facility in accordance with guidelines approved by the Association for Assessment and Accreditation of Laboratory Animal Care (AAALAC). Animals had continuous access to water ad libitum and controlled access to food. Room temperature was maintained at $21^{\circ} \mathrm{C}$. The animals were maintained on a $12 \mathrm{hr}$ light/dark cycle with lights off from 6 PM to 6 AM. The monkeys were maintained with a complete nutritionally balanced diet (Shanghai Shilin Biotechnology, Inc., Shanghai, China) and enriched with seasonal fruits and vegetables. The experimental protocol was approved by the Institutional Animal Care and Use Committee (IACUC) of Crown Bioscience, Inc.

On the experimental day each monkey was fasted overnight and received ketamine $(10 \mathrm{mg} / \mathrm{kg}$, Fujian Gutian Pharmaceutical Co. Ltd., Fujian, China) intramuscular administration. Sedation was maintained with additional ketamine $(5 \mathrm{mg} / \mathrm{kg})$ injection as needed. Xylazine and yohimbine (Sigma-Aldrich Co., St. Louis, MO, USA) were given intramuscularly for testing their effects on blood glucose. Body temperature was maintained during each experiment at $\sim 37^{\circ} \mathrm{C}$ by a thermostatically controlled warm water-circulating pad placed beneath the body. Food and water were provided again after experimental animals were returned to their cages and fully recovered from anesthesia.

\section{Blood collection and handling}

Whole blood samples (1-2 $\mathrm{ml} /$ per time) at various time points after anesthesia or compound treatment were collected from a plastic needle inserted into an arm vein. Samples were collected into an EDTA-washed (0.5 M EDTA, pH 8.0, Gibco, Invitrogen Corporation, Grand Island, NY, USA) 2.5-mL disposable syringe and

Table 1 Characteristics of the diabetic and normoglycemic cynomolgus monkeys used

\begin{tabular}{lcccc}
\hline Monkey & $\mathbf{n}$ & Age (year) & Body weight $(\mathbf{k g})$ & Fasting glucose $(\mathbf{m g} / \mathbf{d L})$ \\
\hline Normal & 5 & $6.8 \pm 0.3$ & $6.7 \pm 0.7$ & $47.9 \pm 5.4$ \\
Diabetic & 5 & $18.3 \pm 0.8^{* * *}$ & $6.0 \pm 0.7$ & $183.6 \pm 29.8^{* * *}$ \\
\hline
\end{tabular}

Values are expressed as the mean \pm SEM. Normal, normoglycemic monkeys; Diabetic, insulin-dependent diabetic monkeys; ${ }^{* * *}, p<0.001 ;$ vs. normal. 
transferred immediately into a $5-\mathrm{ml}$ Monoject ${ }^{\mathrm{Tm}}$ blood collection tube containing $7.5 \mathrm{mg}$ EDTA (Sherwood Medical, St. Louis, MO, USA). The collection tube also contained aprotinin (Sigma-Aldrich Co., St. Louis, MO, USA) for reduction of protein degradation and DPP IV inhibitor (EMD Millipore Corporation, Billerica, MA, USA) for prevention of GLP-1 degradation. Blood samples were centrifuged within $30 \mathrm{~min}$ at $4{ }^{\circ} \mathrm{C}, 3000 \mathrm{~g}$ for $10 \mathrm{~min}$ and then the plasma was separated following standard protocols established in our laboratory. The plasma samples were kept in a freezer at $-80^{\circ} \mathrm{C}$ prior to analysis of glucose, insulin, glucagon, and GLP-1 concentrations.

\section{Intravenous glucose tolerance test (ivGTT)}

To evaluate the $\beta$-cell function ivGTT was performed in the diabetic and normoglycemic monkeys according to the method reported previously [30,31]. The animals were fasted for $16 \mathrm{hrs}$ and anesthetized with an initial dose of ketamine at $15 \mathrm{mg} / \mathrm{kg}$ (i.m.) with additional doses during the procedure if needed. The cephalic and/or saphenous veins were cannulated separately for glucose infusion and blood collection. Glucose $(0.25 \mathrm{~g} / \mathrm{kg}=0.5 \mathrm{ml} / \mathrm{kg}$ of $50 \%$ dextrose) was intravenously infused during $30 \mathrm{sec}$ and the system was flushed with $5 \mathrm{ml}$ heparinized saline to remove residual glucose. Blood was collected immediately before and at 3, 5, 7, 10, 15, 20, 30 min after glucose infusion. Blood samples were immediately transferred to heparinized and chilled tubes on ice. Plasma was then separated and stored at $-80^{\circ} \mathrm{C}$ for subsequent assays.

\section{Hyperinsulinemic-euglycemic clamp}

Hyperinsulinemic-euglycemic clamp analysis was performed in 16-hr-fasted monkeys under ketamine-anesthesia. Cannulation of the cephalic and/or saphenous veins was conducted for insulin and glucose infusion, and blood drawing for glucose measurement. Insulin (biosynthetic human insulin, Novo Nordisk, Denmark) was diluted to $300 \mathrm{mU} / \mathrm{ml}$ by isotonic saline to which $2 \mathrm{ml}$ of the subject's blood per $50 \mathrm{ml}$ was added in order to avoid adhesion of insulin to the syringe plastic surface. Insulin infusion at various rates was given during the 1 st $10 \mathrm{~min}$ to quickly adjust blood glucose near a targeted level. The infusion rate for the hyperinsulinemic-euglycemic clamp was then maintained at $40 \mathrm{mU} / \mathrm{m}^{2}$ Surface Area"min as reported previously [32].

A variable amount of $20 \% \mathrm{D}$-glucose was intravenously infused to maintain blood glucose. Blood samples were taken every $5 \mathrm{~min}$ and glucose was measured by a glucose analyzer (Accu-Chek Active, Roche Diagnostics, Indianapolis, IN, USA) to allow adjustment of the glucose infusion rate accordingly. In the 1st set of experiments, when blood glucose was adjusted and balanced for approximately 120 to $150 \mathrm{~min}$ and then for a 40-min stable period of glucose levels clamped in a range of 55 to $75 \mathrm{mg} / \mathrm{dL}$ under constant infusion of glucose, xylazine was injected intramuscularly. Blood glucose concentration was monitored for another 30 to $40 \mathrm{~min}$ after xylazine injection. In the 2nd set of experiments, xylazine was injected after blood glucose level was adjusted for 95 to $135 \mathrm{~min}$ and then maintained in the range of 55 to $75 \mathrm{mg} / \mathrm{dL}$ for $40 \mathrm{~min}$. The glucose infusion rate was adjusted after xylazine treatment to clamp blood glucose in the range of $55-75 \mathrm{mg} / \mathrm{dL}$. The difference of the glucose metabolic rates ( $M$ rate) was calculated from the glucose infusion rates before and after xylazine treatment.

\section{Data analysis}

Data were expressed as mean \pm SEM. Statistical significance for multiple observation parameters in the same group was determined by One-way Analysis of Variance (ANOVA). If statistical significance of differences was detected, then Tukey's Multiple Comparison Test (GraphPad Software, Inc., La Jolla, CA, USA) was also conducted. The comparison between diabetic and normoglycemic groups was tested by the un-paired $t$-test. Statistical significance was considered if $p$ value was $<0.05$.

\section{Results}

\section{Selection of diabetic monkeys}

As the effects of xylazine on blood glucose had not been studied in NHPs previously, we selected diabetic and normoglycemic monkeys for this study. Based on blood glucose $(<90 \mathrm{mg} / \mathrm{dL})$ and other biochemistry tests, five healthy young cynomolgus monkeys were selected for the normoglycemic group (Table 1). The other five cynomolgus monkeys were selected from spontaneously naturally developed and already insulin-treated diabetic animals with blood glucose $>150 \mathrm{mg} / \mathrm{dL}$. Compared with controls, the diabetic animals were significantly older (Table 1). They received insulin treatment daily because of their high blood glucose, low insulin, and losing body weight if not insulin-treated.

The selected animals were characterized by intravenous glucose tolerance test (ivGTT) and insulin secretion assay. Figure 1A shows that blood glucose and insulin were significantly increased immediately after glucose challenge in normoglycemic monkeys who had normal $\beta$-cell function. The significant increase in blood glucose lasted $20 \mathrm{~min}$ and $15 \mathrm{~min}$ in insulin and then returned to the control levels within $30 \mathrm{~min}$. However, in the insulin-dependent diabetic monkeys only blood glucose was significantly increased without significant alteration of insulin (Figure 1B). The glucose AUC (area under the curve) was significantly higher in the diabetic monkeys than in the normoglycemic ones (Figure $1 C, p<0.01$ ). In contrast, the insulin AUC was significantly lower in the diabetic monkeys than in the normoglycemic ones (Figure 1D, $p<0.05$ ). These results 

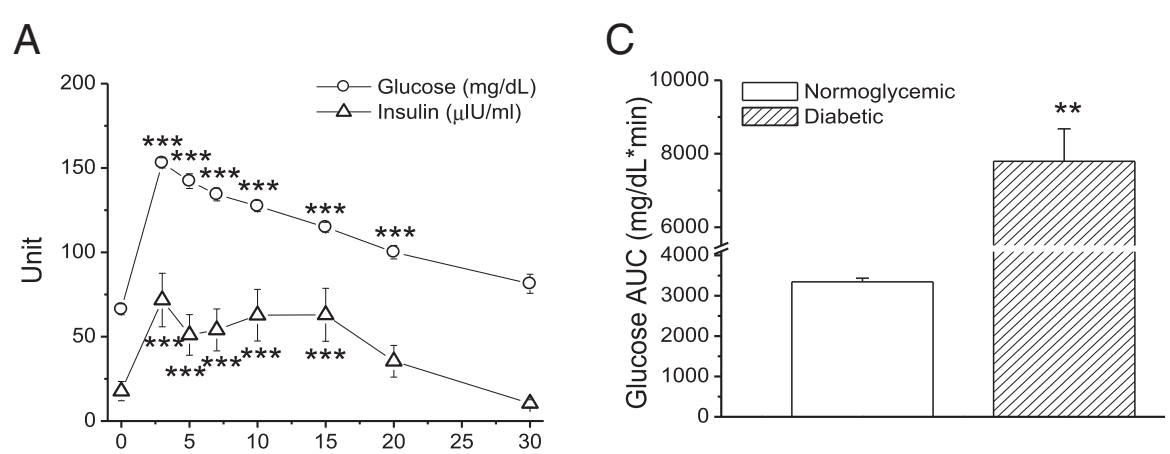

B

D
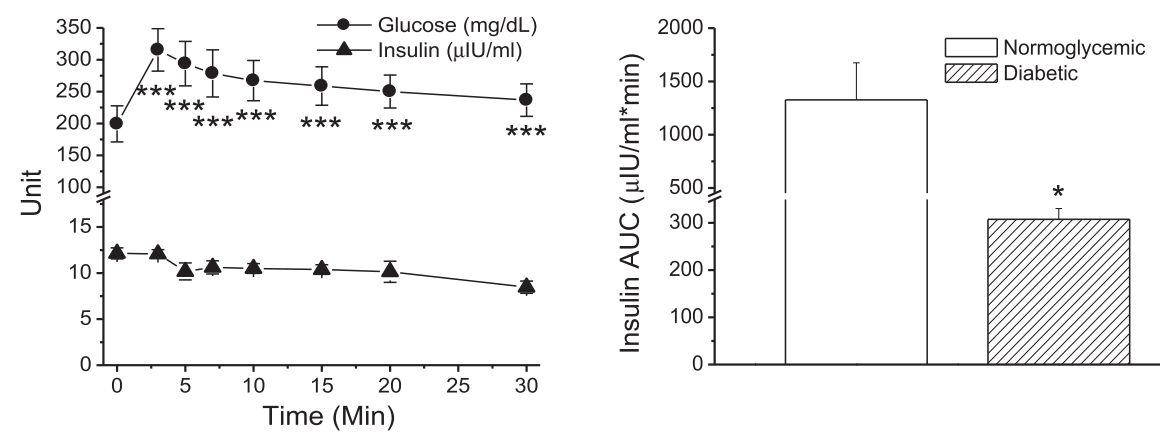

Figure 1 Intravenous glucose tolerance test (ivGTT) in normoglycemic and insulin-dependent diabetic cynomolgus monkeys (Table 1). Plasma glucose and insulin levels were measured at the scheduled time points in normoglycemic (panel $\boldsymbol{A}, \mathrm{n}=5$ ) and insulin-dependent diabetic (panel $\boldsymbol{B}, n=5$ ) monkeys. Panel $\boldsymbol{C}$ shows the glucose AUCs of the ivGTTs for the nomorglycemic (blank bar) and diabetic (strip bar) monkeys. Panel $\boldsymbol{D}$ shows the insulin AUCs of the ivGTTs for the normoglycemic (blank bar) and diabetic (strip bar) monkeys. ${ }^{*}, p<0.05 ;{ }^{* *}, p<0.01$, ***, $p<0.001$; vs. the level at time zero or vs. the normoglycemic group.

indicate that pancreatic function was normal in the normoglycemic monkeys and was significantly impaired in the diabetic ones. To look at the differences between the strains and their xylazine responses, eight normal rhesus monkeys were also used for xylazine test during glucose clamp.

\section{Xylazine-induced hyperglycemia in diabetic and normoglycemic monkeys}

After verification of the pancreatic functions in the selected diabetic and normoglycemic monkeys, the effects of xylazine on blood glucose were investigated. Blood glucose was measured immediately before and at various time points over the $2 \mathrm{hr}$ observation (Figure 2A). Intramuscular injection of xylazine $(1-2 \mathrm{mg} / \mathrm{kg})$ significantly increased blood glucose in a time-dependent manner in the normoglycemic monkeys (Figure 2A, open circle). An initial rise of blood glucose was observed at 5 to $10 \mathrm{~min}$ after xylazine injection. The increase reached the peak of $108 \pm 12 \mathrm{mg} / \mathrm{dL}$ from the baseline of $58 \pm 3 \mathrm{mg} / \mathrm{dL}(p<0.01)$ at approximately 35 min following xylazine administration. Hyperglycemia began to decline approximately $45 \mathrm{~min}$ after xylazine injection. Blood glucose in all of the normoglycemic monkeys gradually returned to the pre-xylazine levels within 2 hrs (Figure 2A, open cycle).
Xylazine-induced hyperglycemia was also observed in the diabetic monkeys $(n=5)$. Xylazine administration $(1-2 \mathrm{mg} / \mathrm{kg})$ increased blood glucose from the baseline of $158 \pm 9 \mathrm{mg} / \mathrm{dL}$ to $221 \pm 13 \mathrm{mg} / \mathrm{dL}$ at approximately $35 \mathrm{~min}$ following the injection $(p<0.05$, Figure 2A, filled cycle). The initial rise and time to the peak after xylazine administration were very similar to those observed in the normoglycemic monkeys. However, the initial decline of blood glucose was delayed to approximately $60 \mathrm{~min}$ after xylazine administration. The decline toward the prexylazine level was much slower in the diabetic monkeys than in the normoglycemic ones (Figure 2A, dot line). Blood glucose remained high 2 hrs after xylazine administration (Figure 2A, filled circle). Only one out of 5 diabetic monkeys gradually returned to the pre-xylazine glucose level at $2 \mathrm{hr}$ after xylazine administration. The other diabetic animals retained their elevated glucose levels $2 \mathrm{hrs}$ after xylazine injection and the $\alpha_{2}$-adrenoceptor antagonist yohimbine $(1-4 \mathrm{mg} / \mathrm{kg})$ was injected to restore blood glucose toward the pre-xylazine levels for safety reason.

\section{Effects of xylazine on glucoregulatory hormones}

To assess the possible mechanism of xylazine-induced hyperglycemia, plasma insulin, glucagon, and GLP-1 were 


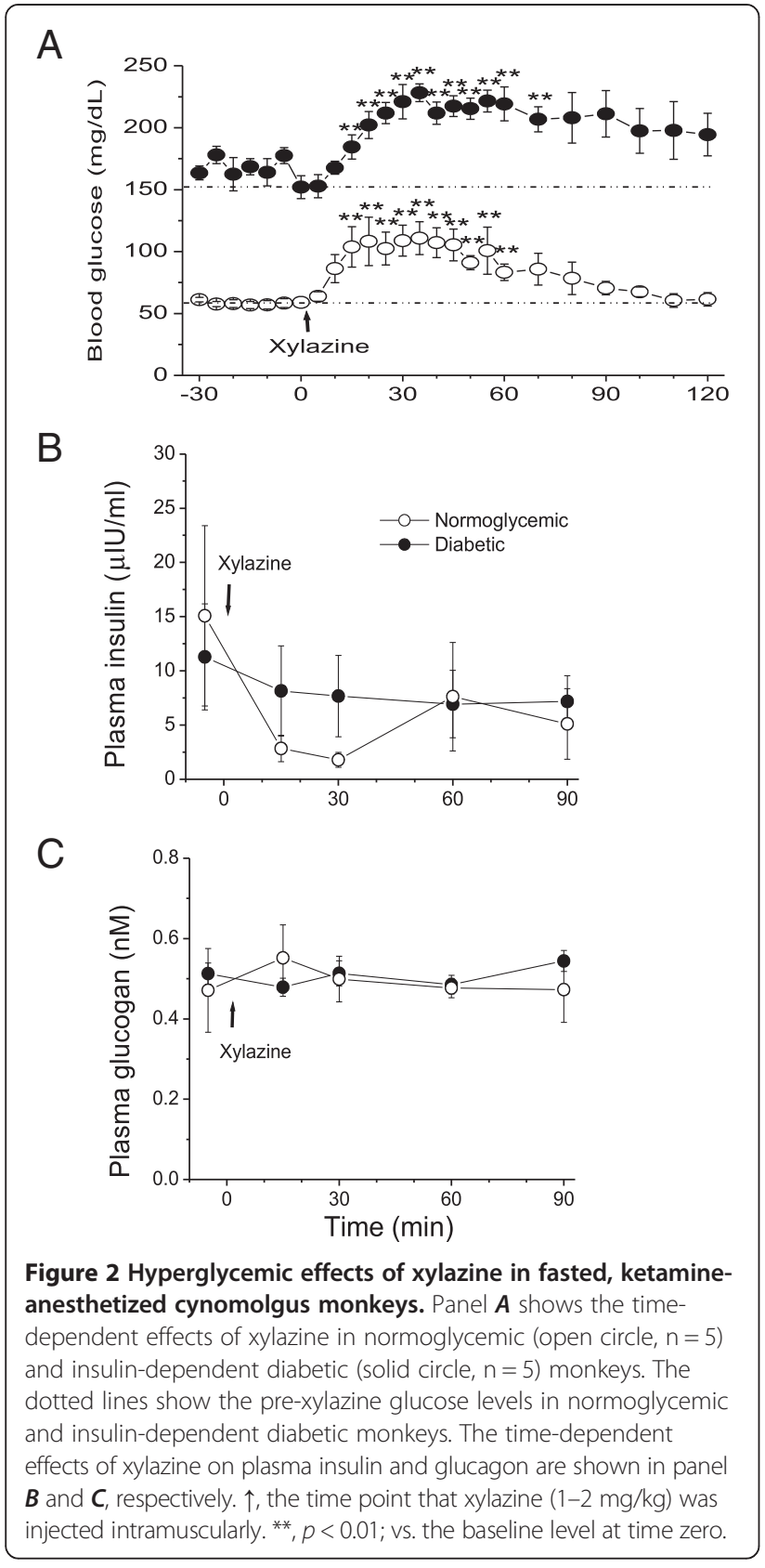

measured in both diabetic and normoglycemic monkeys. As shown in Figure 2B (open cycles), the baseline level of plasma insulin in the normoglycemic monkeys was $15.1 \pm$ $8.3 \mu \mathrm{IU} / \mathrm{ml}(\mathrm{n}=3)$. Xylazine administration $(1-2 \mathrm{mg} / \mathrm{kg})$ did not cause statistically significant alterations of plasma insulin in the non-diabetic monkeys $(p>0.05)$. Compared to the non-diabetes, the plasma insulin level was relatively lower in the diabetic monkeys $(11.2 \pm 4.8 \mu \mathrm{IU} / \mathrm{ml}, \mathrm{n}=5)$ and remained unchanged during 90-min observation after xylazine administration (Figure 2B, solid cycle).

The mean plasma glucagon levels were $0.47 \pm 0.10 \mathrm{nM}$ $(\mathrm{n}=3)$ for the normoglycemic and $0.51 \pm 0.02 \mathrm{nM}(\mathrm{n}=5)$ for the insulin-dependent diabetic monkeys. Xylazine administration $(1-2 \mathrm{mg} / \mathrm{kg})$ did not alter the levels of plasma glucagon in either group (Figure $2 \mathrm{C}, p>0.05$ ). In addition, xylazine had no statistically significant effects on plasma GLP-1 level in both diabetic and normoglycemic monkeys. The baseline plasma GLP-1 level was $1.32 \pm 0.14 \mathrm{pM}(\mathrm{n}=3)$ for the normoglycemic monkeys and $2.52 \pm 0.95 \mathrm{pM}(\mathrm{n}=5)$ for the diabetic ones. The plasma GLP-1 level was $1.50 \pm 0.64 \mathrm{pM}$ for the normoglycemic monkeys and $2.43 \pm 1.39 \mathrm{pM}$ for the diabetic animals at $30 \mathrm{~min}$ after xylazine injection.

\section{Effects of xylazine on blood glucose during hyperinsulinemic-euglycemic clamp}

To exclude or minimize the influence of endogenous insulin on xylazine-induced hyperglycemia and also to see the effects of xylazine on blood glucose in another monkey strain (rhesus), the hyperinsulinemic-euglycemic clamp was performed in normoglycemic rhesus monkeys of either sex $(n=8)$. Their mean age was $10.7 \pm 1.1$ years with the body weight of $7.7 \pm 0.8 \mathrm{~kg}$. Compared with the normoglycemic cynomolgus monkeys (Table 1, $47.9 \pm$ $5.4 \mathrm{mg} / \mathrm{dL}$ ), their blood glucose was significantly higher $(86 \pm 4.6 \mathrm{mg} / \mathrm{dL})$ probably due to their older ages. They were intravenously infused with a constant dose of insulin following an initial bolus infusion in the 1 st $10 \mathrm{~min}$ (Figure 3, open square). Glucose was simultaneously infused with rates adjusted until blood glucose was maintained in a range of 55 to $75 \mathrm{mg} / \mathrm{dL}$ under a constant infusion rate (Figure 3, open triangle). Prior to xylazine injection, a $40 \mathrm{~min}$ period (from 150-190 $\mathrm{min}$ after the initiation of the clamp, Figure 3) of stable blood glucose ranging from 55 to $75 \mathrm{mg} / \mathrm{dL}$ was reached (Figure 3). Administration of xylazine $(2 \mathrm{mg} / \mathrm{kg})$ significantly increased blood glucose level, from $55 \mathrm{mg} / \mathrm{dL}$ (left panel) and $64 \mathrm{mg} / \mathrm{dL}$ (right panel) for pre-xylazine to the peak of $83 \mathrm{mg} / \mathrm{dL}$ (left panel) and $99 \mathrm{mg} / \mathrm{dL}$ (right panel), respectively, despite the glucose infusion rate being unchanged. These results indicate that xylazine still produced hyperglycemia in the presence of clampmaintained hyperinsulinemia which maximally inhibited endogenous negligible insulin secretion.

To further investigate the role of insulin in xylazineinduced hyperglycemia, another set of experiments was conducted in normoglycemic monkeys who were clamped for maintaining hyperinsulinemia to minimize endogenous insulin glucoregulation. When blood glucose in these animals reached 40-min stabilization in a range of 55 to $75 \mathrm{mg} / \mathrm{dL}$ under constant glucose infusion, xylazine ( $2 \mathrm{mg} / \mathrm{kg}$ ) was intramuscularly administrated. In order to hold the blood glucose level in the constant range of 55 to $75 \mathrm{mg} / \mathrm{dL}$ by the negative feedback principle, the glucose infusion rate was significantly reduced, from $14.3 \pm 1.4 \mathrm{mg} / \mathrm{min} / \mathrm{kg}$ for pre-xylazine (Figure 4, open 

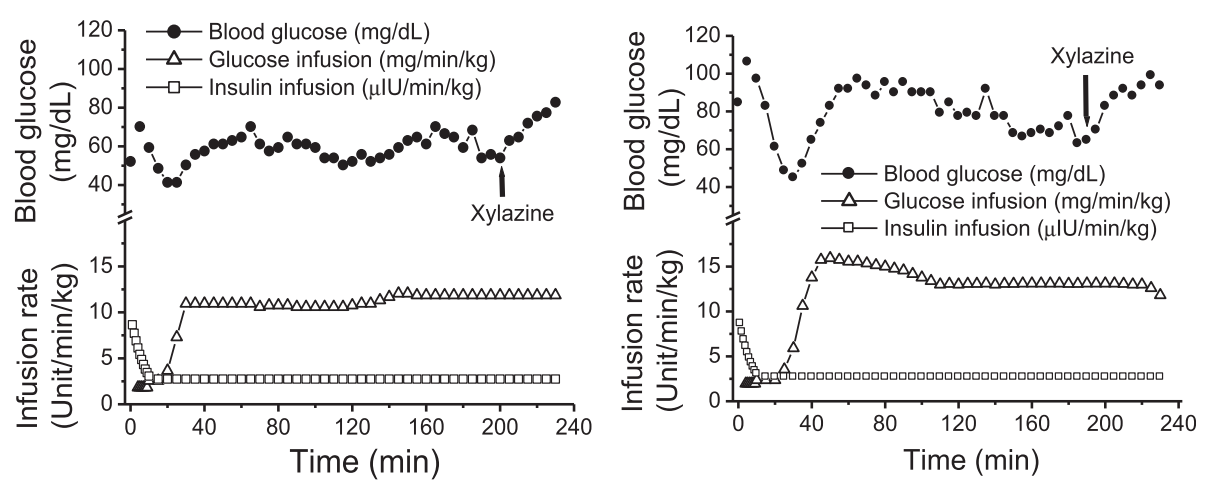

Figure 3 Effects of xylazine on blood glucose concentrations in two fasted normoglycemic rhesus monkeys during the

hyperinsulinemic-euglycemic clamp. Insulin was given with an initial bolus infusion to reduce blood glucose close to a targeted level followed by a constant infusion rate of $40 \mathrm{mU} / \mathrm{m}^{2}$ Surface Area*min (open squares) for maintaining hyperinsulinemia. Glucose was infused simultaneously with adjustable rates to clamp blood glucose in the euglycemic range of $55-75 \mathrm{mg} / \mathrm{dL}$ (open triangles). Xylazine (2 mg/kg) was injected intramuscularly after 40-min euglycemia stabilization to observe its effects on blood glucose when glucose was infused at a constant rate.

bar) to $8.3 \pm 0.8 \mathrm{mg} / \mathrm{min} / \mathrm{kg}$ for post-xylazine (Figure 4 , striped bar, $\mathrm{n}=6, p<0.01)$. Under these steady-state conditions of normoglycemia, the glucose infusion rate equals glucose uptake of the body and is therefore a measure of tissue sensitivity to exogenous insulin. These results support our hypothesis that xylazine-induced hyperglycemia most likely resulted from a reduction of tissue sensitivity to insulin, because blood insulin was stably maintained at a high level by a constant infusion.

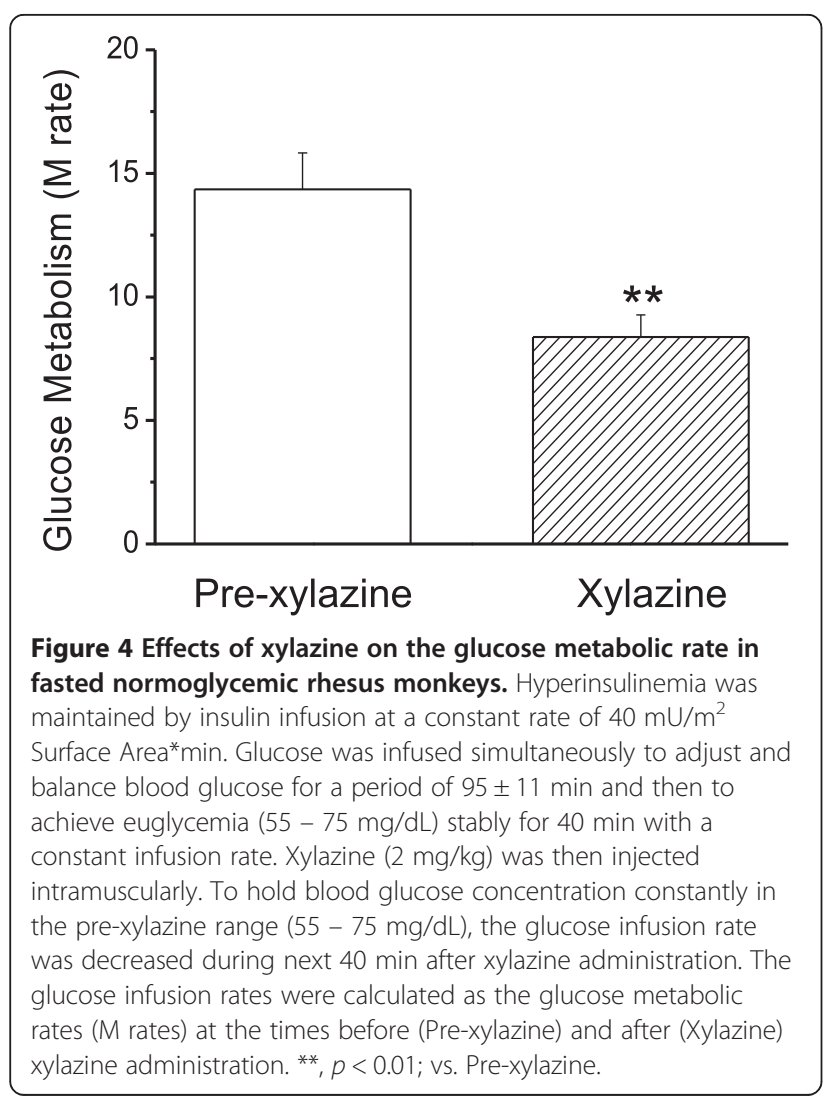

\section{Discussion}

The main finding of this study is that xylazine administration produced an acute hyperglycemia without significant changes in blood insulin, glucagon, and GLP-1 in both insulin-dependent diabetic and normoglycemic monkeys. As xylazine is widely used either alone or combined with other anesthetics, such as ketamine, in various animal research, its hyperglycemia can have an obvious impact on experimental results, especially in diabetic and metabolic research. Xylazine is commonly used as an anesthetic and analgesic in veterinary clinics $[5,6]$. Also, due to increasing amongst drug abusers [20-22], xylazine-induced hyperglycemia potentially becomes a clinically relevant issue, especially in diabetic subjects.

Xylazine-induced hyperglycemia was reported previously in various species, including dogs [11], cattle $[33,34]$, and rats $[12,35]$. However, these studies were performed in normoglycemic animals. These studies led to the hypothesis that the inhibition of insulin secretion plays a critical role in the hyperglycemia. The present study attempts to test this hypothesis in a series of $3 \mathrm{ex}-$ periments. First, we used naturally developed diabetic monkeys who required insulin treatment because their insulin secretory function was greatly diminished. Our data clearly demonstrate that xylazine not only produced profound hyperglycemia in the normoglycemic monkeys, but also in the diabetic animals (Figure 2). Secondly, blood insulin, glucagon, and GLP-1 exhibited no significant changes during the xylazine-induced hyperglycemic period (Figure 2). Thirdly, xylazine still caused hyperglycemia (Figure 3) and decreased glucose uptake ( $\mathrm{M}$ rate, Figure 4) during hyperinsulinemiceuglycemic clamp. These results are consistent with those reported in foals that insulin was not significantly changed during xylazine-produced hyperglycemia [36]. However, xylazine-induced hyperglycemia in rats, sheep, 
cattle, and dogs is associated with a reduction of insulin secretion [35,37-41], while a significant rise in plasma insulin levels occurs in horses [42]. These inconsistent results may be due to different animal species used. Our results suggest that xylazine-induced hyperglycemia results from the decrease of tissue sensitivity to insulin, which leads to the reduction of tissue glucose uptake and utilization.

Xylazine is an analogue of the $\alpha_{2}$-adrenergic agonist clonidine. The effects of activation of $\alpha_{2}$-adrenoceptors on blood glucagon are inconsistent and whether the hyperglycemic effect of xylazine involves glucagon is not clear $[37,43]$. Previous studies in rats showed that xylazine significantly increased blood glucagon, which was not affected by the $\alpha_{2}$-adrenergic antagonist yohimbine $[1,12,35]$. The unchanged glucagon level found in our present study is consistent with the results previously reported in dogs [11]. Glucagon thus seems not so critical for xylazine-induced hyperglycemia at least in NHPs in this study. Furthermore, blood GLP-1 was also not altered after xylazine administration in the present study. Therefore, it is possible that the cause of xylazineinduced hyperglycemia results from stimulation of $\alpha_{2}$ adrenoceptors and then modifying other stress hormones, such as ACTH and GH, which were not measured in our study. However, xylazine has been reported to increase the release of ACTH and $\mathrm{GH}$ in cattle and dogs [3,39].

It is unclear whether xylazine itself could increase hepatic glucose production (glycogenolysis and gluconeogenesis) and then cause hyperglycemia. However, as xylazine-induced hyperglycemia observed in the present study was conducted in fasted monkeys which had reduced glycogen stores [44], the contribution of glycogenolysis to the hyperglycemia was very unlikely, especially in fasted insulin-dependent diabetic monkeys. In addition, the level of blood glucagon (the stimulating hormone of glycogenolysis and gluconeogenesis) was not increased in the presence of xylazine (Figure 2C). Therefore, xylazine-induced hyperglycemia was unlikely via an increase in hepatic glucose production.

Compared with the insulin-dependent diabetic monkeys, the decline of xylazine-induced hyperglycemia was faster and blood glucose returned to the prexylazine level within $90 \mathrm{~min}$ in normoglycemic monkeys (Figure 2A). In contrast, blood glucose remained elevated during the entire observation period of $120 \mathrm{~min}$ in the diabetic monkeys. The specific $\alpha_{2}$-adrenoceptor antagonist yohimbine had to be given in 4 out of 5 insulin dependent diabetic monkeys to decrease their blood glucose to the pre-xylazine level for animal safety reason. These results suggest that xylazine-induced hyperglycemia is mediated, at least partially, via stimulation of $\alpha_{2}$ adrenoceptors. Lattermann and colleagues reported that blood glucose concentrations were significantly increased in patients during and after lower abdominal surgery [45]. However, compared with control patients (saline), intraoperative glucose plasma concentrations were even higher in the patients who received clonidine $(1 \mu \mathrm{g} / \mathrm{kg})$ $30 \mathrm{~min}$ before induction of general anesthesia. The adverse effects of hyperglycemia can be reflected in animal models of myocardial infarction [46] and in patients after acute myocardial infarction [47], stroke [48], and cardiac surgery [49]. Therefore, great care should be taken to avoid using an agent which causes hyperglycemia and influences outcome.

Due to the difficulty of obtaining traditional illicit drugs, consumption in drug abusers is turning towards less restricted compounds. Xylazine, the veterinary sedative anesthetic, was confirmed as the anesthetic substance used in Puerto Rico by testing exchanged needles in 29 sites in 11 municipalities [22]. Xylazine used as adulterants in heroin was also found in drug related deaths in Philadelphia, Pennsylvania [20,50]. An 18-year-old man after inhaling xylazine showed chills and dizziness followed by sweating, gait instability, palpitations and syncope with bradycardia and hypotension. More cases of toxicity caused by xylazine consumption have been documented in humans, occasionally resulting in death $[18,20,28]$. Xylazine users could become apneic and require intubation and mechanical ventilation. Two critical issues about chronic use of xylazine are the physical dependence and the noticeable open skin ulcers [6]. These ulcers are referred to as abscesses and are a serious health concern. The pain caused by the ulcers promotes further injections of xylazine because of its sedative/anesthetic effects. These open skin ulcers emit a strong odor, ooze, and in severe cases limit the mobility of the extremities with a possibility of amputation [25]. In xylazine abusers (generally male with a mean age of 30 years) 35\% have skin lesions, which leads to more social exclusion. It is unclear whether the skin ulcers result from the hyperglycemic effect of xylazine in abusers, because extremity infection in diabetic patients is common and severe, sometimes difficult to cure [22]. More experiments are thus required to elucidate how xylazine induces hyperglycemia at the cellular and molecular levels, which may have clinical relevance.

\section{Conclusions}

In conclusion, the anesthetic xylazine can cause acute hyperglycemia with no significant alterations of blood insulin, glucagon, and GLP-1 in normoglycemic and insulin-dependent diabetic non-human primates. Such hyperglycemia is most likely via xylazine stimulation of $\alpha_{2}$-adrenoceptors and subsequent reduction of tissue sensitivity to insulin and glucose uptake.

Competing interests

All of the authors are employees of Crown Bioscience, Inc. 


\section{Authors' contributions}

YXW and MB designed the experiments, BW, XW and FD collected the data, $X W$ and YFX analyzed the data, YFX, MB and YXW drafted the manuscript. All authors read and approved the final manuscript.

Received: 2 May 2013 Accepted: 15 October 2013

Published: 20 October 2013

\section{References}

1. Peng M, Li Y, Luo Z, Liu C, Laties AM, Wen R: Alpha2-adrenergic agonists selectively activate extracellular signal-regulated kinases in Muller cells in vivo. Invest Ophthalmol Vis Sci 1998, 39(9):1721-1726.

2. Gallanosa AG, Spyker DA, Shipe JR, Morris DL: Human xylazine overdose: a comparative review with clonidine, phenothiazines, and tricyclic antidepressants. Clin Toxicol 1981, 18(6):663-678.

3. Hampshire J, Altszuler N: Clonidine or xylazine as provocative tests for growth hormone secretion in the dog. Am J Vet Res 1981, 42(6):1073-1076.

4. Tita B, Leone MG, Casini ML, Corubolo C, Bordi F, Guidolin D, Fumagalli E, Romanelli L, Mattioli F, Feher J, et al: Corneal toxicity of xylazine and clonidine, in combination with ketamine, in the rat. Ophthalmic Res 2001, 33(6):345-352.

5. Banknieder AR, Phillips JM, Jackson KT, Vinal SI Jr: Comparison of ketmine with the combination of ketamine and xylazine for effective anesthesia in the rhesus monkey (Macaca mulatta). Lab Anim Sci 1978, 28(6):742-745.

6. Wright M: Pharmacologic effects of ketamine and its use in veterinary medicine. J Am Vet Med Assoc 1982, 180(12):1462-1471.

7. Green CJ, Knight J, Precious S, Simpkin S: Ketamine alone and combined with diazepam or xylazine in laboratory animals: a 10 year experience. Lab Anim 1981, 15(2):163-170.

8. Naccarato EF, Hunter WS: Anaesthetic effects of various ratios of ketamine and xylazine in rhesus monkeys (Macacca mulatta). Lab Anim 1979, 13(4):317-319.

9. El Motal SM A, Sharp GW: Inhibition of glucose-induced insulin release by xylazine. Endocrinology 1985, 116(6):2337-2340.

10. Stewart MC, English AW: The reversal of xylazine/ketamine immobilisation of fallow deer with yohimbine. Aust Vet J 1990, 67(9):315-317.

11. Ambrisko TD, Hikasa Y: Neurohormonal and metabolic effects of medetomidine compared with xylazine in beagle dogs. Can J Vet Res 2002, 66(1):42-49.

12. Saha JK, Xia J, Engle SK, Chen YF, Glaesner W, Jakubowski JA: A model of controlled acute hyperglycemia in rats: effects of insulin and glucagonlike peptide-1 analog. J Pharmacol Exp Ther 2006, 316(3):1159-1164

13. Martin IK, McDonald IR: Adrenocortical functions in a macropodid marsupial thylogale billardierii. J Endocrinol 1986, 110(3):471-480.

14. Ambrisko TD, Hikasa Y, Sato K: Influence of medetomidine on stressrelated neurohormonal and metabolic effects caused by butorphanol, fentanyl, and ketamine administration in dogs. Am J Vet Res 2005, 66(3):406-412

15. Brown ET, Umino Y, Loi T, Solessio E, Barlow R: Anesthesia can cause sustained hyperglycemia in C57/BL6J mice. Vis Neurosci 2005, 22(5):615-618.

16. Kanda T, Hikasa Y: Neurohormonal and metabolic effects of medetomidine compared with xylazine in healthy cats. Can J Vet Res 2008, 72(3):278-286

17. Fyffe JJ: Effects of xylazine on humans: a review. Aust Vet J 1994, 71(9):294-295

18. Elejalde Jl, Louis CJ, Elcuaz R, Pinillos MA: Drug abuse with inhalated xylazine. Eur J Emerg Med 2003, 10(3):252-253.

19. Capraro AJ, Wiley JF 2nd, Tucker JR: Severe intoxication from xylazine inhalation. Pediatr Emerg Care 2001, 17(6):447-448

20. Wong SC, Curtis JA, Wingert WE: Concurrent detection of heroin, fentanyl, and xylazine in seven drug-related deaths reported from the Philadelphia medical Examiner's office. J Forensic Sci 2008, 53(2):495-498.

21. Torruella RA: Xylazine (veterinary sedative) use in Puerto Rico. Subst Abuse Treat Prev Policy 2011, 6:7

22. Rodriguez N, Vargas Vidot J, Panelli J, Colon H, Ritchie B, Yamamura Y: GCMS confirmation of xylazine (Rompun), a veterinary sedative, in exchanged needles. Drug Alcohol Depend 2008, 96(3):290-293.

23. Reyes JC, Negron JL, Colon HM, Padilla AM, Millan MY, Matos TD, Robles RR: The emerging of xylazine as a new drug of abuse and its health consequences among drug users in Puerto Rico. J Urban Health 2012, 89(3):519-526.

24. Lopez Briz E, Barreda Aznar A, Guevara Serrano J, Blasco M: Veterinary drugs: a new source of drug abuse? Med Clin (Barc) 1991, 96(11):437.

25. Room R: Stigma, social inequality and alcohol and drug use. Drug Alcohol Rev 2005, 24(2):143-155.

26. Liu CM, Chiu MJ, Fang CC, Chen WJ: Xylazine abuse: a rare cause of syncope. Clin Toxicol (Phila) 2007, 45(3):309-311.

27. Poklis A, Mackell MA, Case ME: Xylazine in human tissue and fluids in a case of fatal drug abuse. J Anal Toxicol 1985, 9(5):234-236.

28. Moore KA, Ripple MG, Sakinedzad S, Levine B, Fowler DR: Tissue distribution of xylazine in a suicide by hanging. J Anal Toxicol 2003, 27(2):110-112

29. Mittleman RE, Hearn WL, Hime GW: Xylazine toxicity-literature review and report of two cases. J Forensic Sci 1998, 43(2):400-402.

30. Hansen $B C$ : Investigation and treatment of type 2 diabetes in nonhuman primates. Methods Mol Biol 2012, 933:177-185.

31. Hansen BC, Bodkin NL: Standardization of IVGTT. Importance of method used to calculate glucose disappearance. Diabetes Care 1993, 16(5):847.

32. DeFronzo RA, Tobin JD, Andres R: Glucose clamp technique: a method for quantifying insulin secretion and resistance. Am J Physiol 1979, 237(3):E214-E223.

33. Eichner RD, Prior RL, Kvasnicka WG: Xylazine-induced hyperglycemia in beef cattle. Am J Vet Res 1979, 40(1):127-129.

34. Brearley JC, Dobson H, Jones RS: Investigations into the effect of two sedatives on the stress response in cattle. J Vet Pharmacol Ther 1990, 13(4):367-377.

35. Saha JK, Xia J, Grondin JM, Engle SK, Jakubowski JA: Acute hyperglycemia induced by ketamine/xylazine anesthesia in rats: mechanisms and implications for preclinical models. Exp Biol Med (Maywood) 2005, 230(10):777-784

36. Robertson SA, Carter SW, Donovan M, Steele C: Effects of intravenous xylazine hydrochloride on blood glucose, plasma insulin and rectal temperature in neonatal foals. Equine Vet J 1990, 22(1):43-47.

37. Goldfine ID, Arieff Al: Rapid inibition of basal and glucose-stimulated insulin release by xylazine. Endocrinology 1979, 105(4):920-922.

38. Muggaberg J, Brockman RP: Effect of adrenergic drugs on glucose and plasma glucagon and insulin responses to xylazine in sheep. Res Vet $\mathrm{SCl}$ 1982, 33(1):118-120.

39. Kasuya E, Hodate K, Matsumoto M, Sakaguchi M, Hashizume T, Kanematsu S: The effects of xylazine on plasma concentrations of growth hormone, insulin-like growth factor-l, glucose and insulin in calves. Endocr J 1996, 43(2):145-149

40. Kasuya E, Hodate K, Matsumoto M, Sakaguchi M, Hashizume T, Kanematsu S: Effects of atipamezole, an alpha 2-adrenergic antagonist, and somatostatin on xylazine-induced growth hormone release in calves. Endocr J 1996, 43(5):551-556.

41. Rizk A, Herdtweck S, Meyer H, Offinger J, Zaghloul A, Rehage J: Effects of xylazine hydrochloride on hormonal, metabolic, and cardiorespiratory stress responses to lateral recumbency and claw trimming in dairy cows. J Am Vet Med Assoc 2012, 240(10):1223-1230.

42. Robertson SA, Steele CJ, Chen CL: Metabolic and hormonal changes associated with arthroscopic surgery in the horse. Equine Vet J 1990, 22(5):313-316

43. Brockman RP: Effect of xylazine on plasma glucose, glucagon and insulin concentrations in sheep. Res Vet Sci 1981, 30(3):383-384.

44. Geary N, Langhans W, Scharrer E: Metabolic concomitants of glucagoninduced suppression of feeding in the rat. Am J Physiol 1981, 241(5):R330-R335

45. Lattermann $R$, Schricker $T$, Georgieff M, Schreiber M: Low dose clonidine premedication accentuates the hyperglycemic response to surgery. Can J Anaesth 2001, 48(8):755-759.

46. Shiomi T, Tsutsui $H$, Ikeuchi M, Matsusaka H, Hayashidani S, Suematsu N, Wen J, Kubota T, Takeshita A: Streptozotocin-induced hyperglycemia exacerbates left ventricular remodeling and failure after experimental myocardial infarction. J Am Coll Cardiol 2003, 42(1):165-172.

47. Capes SE, Hunt D, Malmberg K, Gerstein HC: Stress hyperglycaemia and increased risk of death after myocardial infarction in patients with and without diabetes: a systematic overview. Lancet 2000, 355(9206):773-778

48. Scott JF, Robinson GM, French JM, O'Connell JE, Alberti KG, Gray CS: Blood pressure response to glucose potassium insulin therapy in patients with 
acute stroke with mild to moderate hyperglycaemia. I Neurol Neurosurg Psychiatry 2001, 70(3):401-404.

49. Van den Berghe $G$, Wouters $P$, Weekers F, Verwaest $C$, Bruyninckx F, Schetz $M$, Vlasselaers D, Ferdinande P, Lauwers P, Bouillon R: Intensive insulin therapy in critically ill patients. N Engl J Med 2001, 345(19):1359-1367.

50. Hsu WH, Hummel SK: Xylazine-induced hyperglycemia in cattle: a possible involvement of alpha 2-adrenergic receptors regulating insulin release. Endocrinology 1981, 109(3):825-829.

doi:10.1186/1471-2253-13-33

Cite this article as: Xiao et al:: Xylazine-induced reduction of tissue sensitivity to insulin leads to acute hyperglycemia in diabetic and normoglycemic monkeys. BMC Anesthesiology 2013 13:33.

\section{Submit your next manuscript to BioMed Central and take full advantage of:}

- Convenient online submission

- Thorough peer review

- No space constraints or color figure charges

- Immediate publication on acceptance

- Inclusion in PubMed, CAS, Scopus and Google Scholar

- Research which is freely available for redistribution 